\title{
Radiation oncology as part of medical education-current status and possible digital future prospects
}

\author{
Hendrik Dapper ${ }^{1}$ Marjo Wijnen-Meijer ${ }^{2} \cdot$ Salome Rathfelder $^{3} \cdot$ Katharina Mosene $^{2} \cdot$ Isabelle von Kirchbauer $^{2}$. \\ Denise Bernhardt ${ }^{1}$. Pascal O. Berberat ${ }^{2}$. Stephanie E. Combs ${ }^{1,4,5}$
}

Received: 10 August 2020 / Accepted: 2 November 2020 / Published online: 23 November 2020

(c) The Author(s) 2020

\begin{abstract}
Purpose Education as part of medical education is currently changing rapidly. Not least because of the corona crisis, more and more digital teaching formats and innovative teaching concepts such as the flipped classroom model are finding their way into teaching. We analyzed the acceptance and effectiveness of traditional teaching methods as well as the interest in innovative e-learning methods among medical students in the field of radiation oncology at the medical school of the Technical University of Munich.

Methods We carried out an online-based survey as well as a knowledge test on all students from two terms who had completed the seminar series of radiation oncology. The survey comprised seven questions on the frequency of participation, acceptance, and judgment of the effectiveness in terms of learning and on a potential use of e-learning methods using a six-point Likert scale. The test consisted of 10 multiple-choice questions.

Results Traditional teaching methods are largely accepted by students and most students consider the current learning format to be effective in terms of the teaching effect in the field of radiation oncology. However, only about $50 \%$ of all knowledge questions were answered correctly. The possible use of e-learning methods was judged critically or desired in roughly equal parts among the students.

Conclusion Traditional seminars enjoy a high level of acceptance among students. Effectiveness with regard to the internalization of content taught, however, should be increased. After all, the future seems to lie in the integration of e-learning in the form of educational videos and practical seminars.
\end{abstract}

Keywords Radiation oncology $\cdot$ Education $\cdot$ E-learning $\cdot$ Flipped classroom $\cdot$ Seminars

Availability of data and materials The present data are summarized in this paper (Methods). The complete dataset can be retrieved from the authors upon formal request from interested readers

Dr. med. Hendrik Dapper, M.D.

hendrik.dapper@mri.tum.de

Prof. Dr. Marjo Wijnen-Meijer

marjo.wijnen-meijer@tum.de

Salome Rathfelder

salome.rathfelder@drf-luftrettung.de

Katharina Mosene

katharina.mosene@tum.de

Isabelle von Kirchbauer

i.kirchbauer@tum.de

Dr. med. Denise Bernhardt

denise.bernhardt@mri.tum.de

Univ.-Prof. Dr. Pascal O. Berberat

berberat@tum.de
Univ.-Prof. Dr. med. Stephanie E. Combs

stephanie.combs@tum.de

1 Department of Radiation Oncology, Klinikum rechts der Isar, Technical University Munich, Ismaninger Str. 22, 81675 Munich, Germany

2 School of Medicine, TUM Medical Education Center, Technical University Munich, Nigerstraße 3, 81675 Munich, Germany

3 DRF Stiftung Luftrettung gAG, Rita-Maiburg-Straße 2, 70794 Filderstadt, Germany

4 Institute for Radiation Medicine (IRM), Helmholtz Zentrum München (HMGU), Ingolstädter Landstr. 1, Neuherberg, Germany

5 Partner Site Munich, Deutsches Konsortium für Translationale Krebsforschung (DKTK), Munich, Germany 


\section{Background}

Like many other fields of study, undergraduate medical education in Germany has undergone extensive changes in the past years. Although various innovative practice-oriented and case-oriented alternative types of education exist, the vast majority of medical students find themselves in the traditional one-dimensional teaching format for most of their time [1-3]. The Ohio State University College of Medicine conducted a survey and identified the most important components of medical education: next to clinical problem solving, learning how to acquire knowledge, developing bedside manner, teamwork, technology training, and clinical research were among the top six aspects [4]. All of these aspects require a high degree of reflection, empathy, teamwork, and practical skills, which must all be based on profound knowledge. While classroom teaching (with an expert lecturing and presenting information and students acting as passive listeners) has been the method of teaching for decades, innovative courses are replacing this traditional teaching method more and more and give students a more active role in an interactive setting. They are very well accepted among students [5]. A restructuring of the medical curriculum is therefore called for by education experts [6].

Introduction of new teaching methods in medical schools is driven to a large extent by digitalization. More and more digital formats find their way into medical education and are used by most students [7, 8]. One of the promising e-learning formats is the "flipped classroom" [9]. According to this format, learning is divided into two steps. Firstly, students perform some pre-class activities [10]. For example, students watch an instructional video on their own, whenever and wherever they like. They learn the essential content of the video by themselves. In a second phase, students apply the knowledge acquired in interactive small group sessions facilitated by an expert [11]. In Germany, medical education remains very traditional, which is particularly true for the curriculum and the prerequisites, due to the central management of teaching and learning content as well as nationwide assessment and state examinations.

The COVID-19 crisis has not only pushed digital health but also led to social distancing in hospitals, to protect patients, medical workers, and students. As a consequence, face-to-face teaching was abandoned at many universities. The crisis thus promoted the necessity of employing digital teaching formats and, as a result, revealed their benefits [12, 13].

Besides surgery and clinical oncology, radiation oncology is one of the three main pillars in oncological therapy and is used for almost every tumor entity, depending on the stage of the tumor and the intention of tumor therapy $[1,14]$. Due to its interdisciplinary importance and the fact that around two thirds of all tumor patients receive radiation therapy in the course of their disease, basic knowledge of indications and practical and technical implementation, as well as of clinically relevant aspects such as side effects and supportive therapies, should be taught to prospective physicians regardless of their final specialization $[1,15$, 16].

At our medical school, radiation oncology seminars have so far been performed in the traditional form of face-to-face teaching. The teacher generally plays an active role, while the students mostly just absorb the information given and only start springing into action when they ask or are asked questions. In comparison to traditional lectures, however, there is at least a practical aspect to seminars, as they are closer to everyday clinical practice and mostly have a more intensive character due to the small groups. Therefore, seminars are generally very popular among students [17].

The aim of the study described in this article was to analyze the acceptance and effectiveness of traditional teaching methods in seminars, in this case radiation oncology education. Furthermore, we tried to find out to what extent students accept innovative e-learning methods.

\section{Methods}

The curriculum for medical education in Germany currently consists of four preclinical and six clinical semesters followed by two practical semesters. In accordance with the clinical curriculum of the medical school of the Technical University of Munich, radiation oncology (lectures and seminars) is currently taught together with radiology and nuclear medicine in a cross-sectional course called "imaging procedures, radiation therapy, and radiation protection." It takes place in the first or second clinical semester and also in the third year of medical school. As about 160 students per semester have to take this course, but since for the seminars a group of 16 students is the maximum, each session has to be scheduled ten times per semester. With regard to radiation oncology, the course includes five different seminars of $45 \mathrm{~min}$ each. These seminars are compulsory, and every student has to attend them with the allowance of missing one session. The topics of these seminars are radiation biology, oncological informed consent discussion, radiotherapy process and linear accelerator, treatment planning, and brachytherapy. The main content of these seminars is summarized in Table 1.

\section{Procedure for and implementation of the five seminars}

The course of the five seminars is structured as follows: from the students' perspective, all five seminars take place 
Table 1 Seminar series "Radiation Oncology" at the Technical University of Munich

\begin{tabular}{|c|c|c|c|}
\hline & Subject of the seminar & Main content; 45 min each & Implementation \\
\hline 1 & Radiation biology & $\begin{array}{l}\text { Definition of energy dose and radiation effects in cells } \\
\text { Four R's of radiotherapy, therapeutic breadth } \\
\text { Time scale of radiation effects in normal and tumor cells } \\
\text { Assays to measure radiation effects }\end{array}$ & $\begin{array}{l}\text { PowerPoint lecture given by radiation } \\
\text { biologist } \\
\text { Tour of the laboratory of radiation } \\
\text { biology }\end{array}$ \\
\hline 2 & $\begin{array}{l}\text { Oncological informed } \\
\text { consent discussion }\end{array}$ & $\begin{array}{l}\text { Basics in conducting sensitive oncological conversations } \\
\text { Procedure and implementation of clarification talks } \\
\text { Indication, effects, and side effects of radiation therapy } \\
\text { Legal aspects of clarification talks }\end{array}$ & $\begin{array}{l}\text { Lecture given by a radiation } \\
\text { oncologist } \\
\text { Presentation and discussion of an } \\
\text { information sheet for patients }\end{array}$ \\
\hline 3 & $\begin{array}{l}\text { Radiation therapy } \\
\text { process and linear } \\
\text { accelerator }\end{array}$ & $\begin{array}{l}\text { Implementation of the planning CT and patient positioning } \\
\text { Target volume definitions and consideration of organs at risk } \\
\text { Structure and functionality of linear accelerators } \\
\text { The process of a radiation therapy session, image guidance }\end{array}$ & $\begin{array}{l}\text { Lecture given by a radiation } \\
\text { oncologist } \\
\text { Brief demonstration of the linear } \\
\text { accelerator and an irradiation session }\end{array}$ \\
\hline 4 & Treatment planning & $\begin{array}{l}\text { Physical basics and properties of different therapeutic radiation } \\
\text { Important physical parameters in radiation therapy } \\
\text { Presentation of radiation plans and dose-volume histograms } \\
\text { Irradiation techniques (3D-RT, IMRT, IGRT) }\end{array}$ & $\begin{array}{l}\text { PowerPoint lecture given by } \\
\text { a radiation physicist } \\
\text { Presentation of radiation plans and } \\
\text { DVHs using radiation software }\end{array}$ \\
\hline 5 & Brachytherapy & $\begin{array}{l}\text { Different emitters and physical properties (LDR, HDR) } \\
\text { Different methods of application of brachytherapy } \\
\text { Indication, planning, and implementation of brachytherapy } \\
\text { Special aspects of radiation protection }\end{array}$ & $\begin{array}{l}\text { PowerPoint lecture given by } \\
\text { a radiation oncologist } \\
\text { Tour of the premises and } \\
\text { demonstration of brachytherapy } \\
\text { equipment }\end{array}$ \\
\hline
\end{tabular}

on a weekly basis with the succession of the seminars depending on the student group. Each seminar unit is held in a small group of up to 16 students by an expert in the respective field, and takes a total of $45 \mathrm{~min}$. From the teachers' perspective, two teachers divide up their ten times of teaching the same subject. All five seminars are facilitated by the respective expert by means of a lecture. This lecture normally takes 20 to $25 \mathrm{~min}$. Afterwards, equipment, premises, software applications, information sheets, or processes are also introduced to the students in 20 to $25 \mathrm{~min}$, depending on the type of seminar (Table 1). It depends on the teacher to what extent students may get actively involved in class during lectures, presentations, and discussions arising from questions asked by students. These questions usually may be asked either during or at the end of each seminar. It is the teachers' task to check the students' presence and to sign a routing slip at each seminar. In addition, each student receives a handout of one to two pages (size DIN A4) at the end of each seminar which summarizes the main content of the lecture in key points and by means of graphics.

\section{Survey}

For our survey we made use of Evasys, which is a chargeable web-based survey tool invented by the Electric Paper Evaluationssysteme GmbH (Lüneburg, Germany) [18]. This tool provides an automated evaluation of the number of participants, mean and median values, standard deviation, most frequent answers, and percentage of the respective answers. These results are displayed in both absolute numbers with one decimal place and in graphics. A total of 17 questions were drawn up. Only one out of five (knowledge test) and six (opinion) answers, respectively, was to be chosen.

The survey was divided into two sections.

- The first section related to the personal opinion of the students and comprised seven questions on the frequency of participation, acceptance, and judgment of the effectiveness in terms of learning, and on a potential use of e-learning methods in connection with the radiation oncology seminars. In most cases, students were supposed to choose one answer on a six-point Likert scale from "does not apply at all" to "fully applies."

- The second section consisted of a total of ten knowledge questions, two for each seminar topic. Five options for an answer to each question were presented, out of which the students had to choose the correct one (multiple-choice questions). The quality criteria applied to our questions matched those of criteria for high-quality multiple-choice questions (clear question style, high degree of clarity of the answer options, no hidden clues, equal length of the answer options, questions should be able to be answered even without the answer options being visible) [19]. The knowledge test should take place 1 to 7 weeks after the last seminar to ensure long-term memory testing, but without too much time to the seminars. 
1. How many seminars in the field of radiotherapy did you attend (brachytherapy, radiation biology, treatment planning, linear accelerator, explanatory conversation with the patient)?

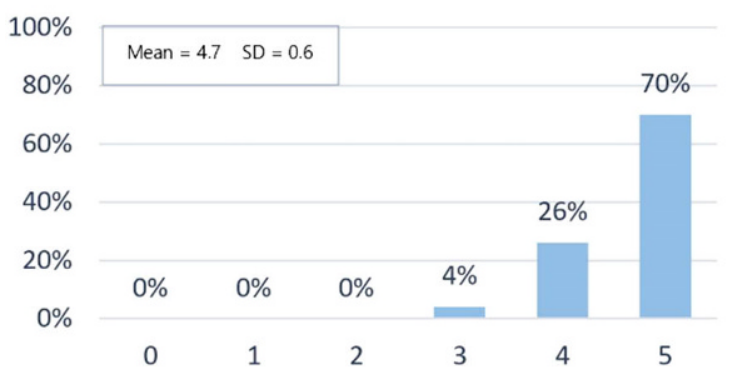

3. I liked the way in which knowledge was transferred (lecture, material, etc.) in the seminar series "radiotherapy".

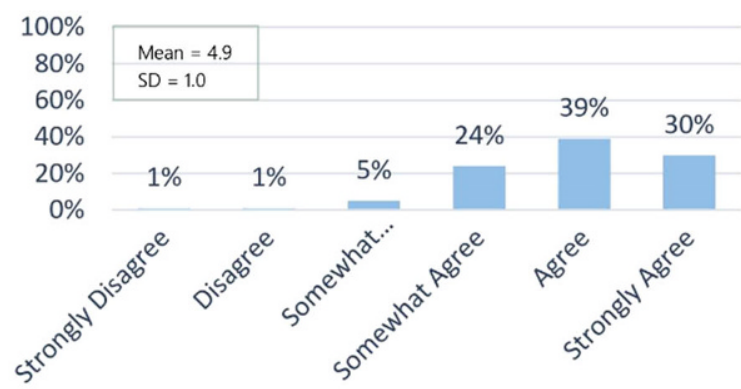

5. I think the overall time to be invested in the seminar series is in accordance with the knowledge acquired when learning the contents prescribed.

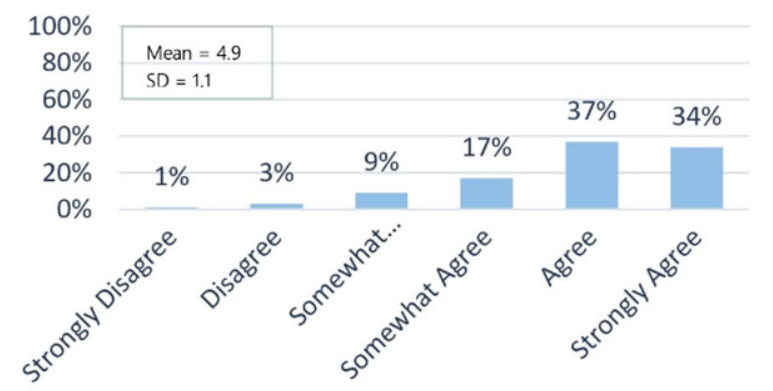

7. I think a short instructional video of 10 to 15 minutes before each seminar unit and additional studies in small groups during the seminar would have made a lot of sense.

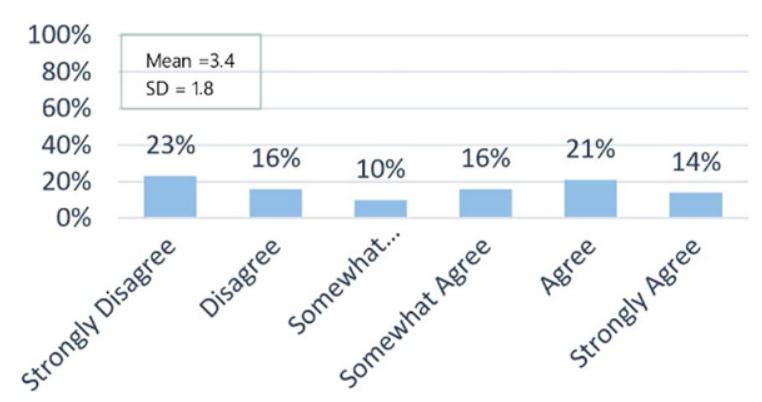

2. I liked the seminar series "radiotherapy" (brachytherapy, radiation biology, treatment planning, linear accelerator, explanatory conversation with the patient) altogether.

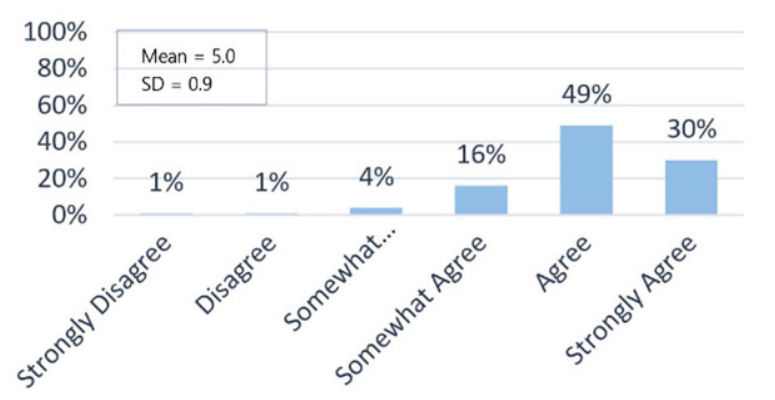

4. I think I was able to deepen the major educational content in the long term.

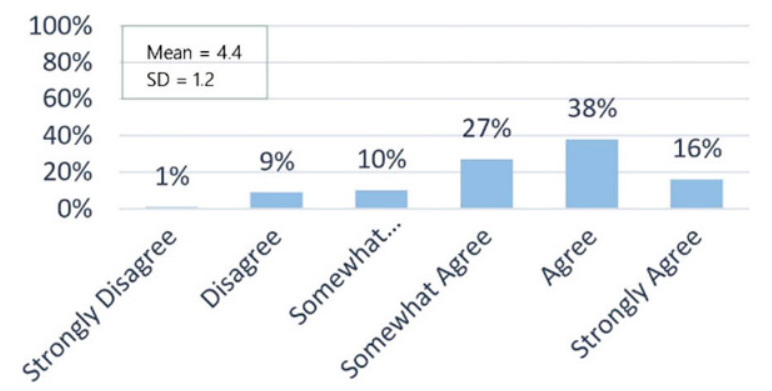

6. I think I probably would have learned the objects of learning better at the same time spent on learning if I had studied in a different way (private study, Youtube videos, etc.)

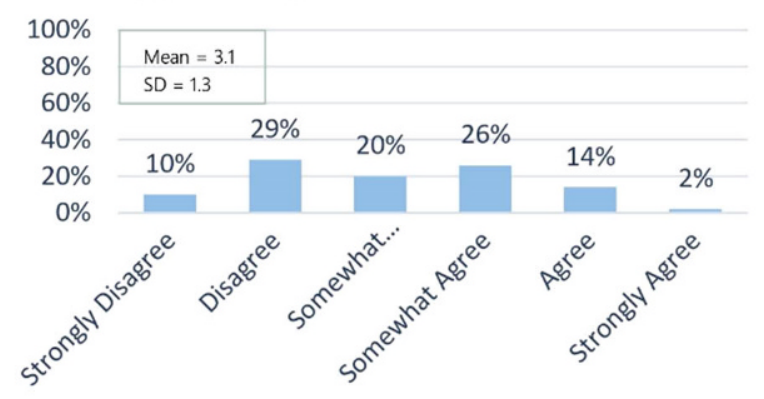

Fig. 1 Participation, acceptance, assessment of the effectiveness in terms of learning, and on a potential use of e-learning methods among medical students in connection with radiation oncology seminars 
One to two weeks after the end of the final seminar, each student was asked in an email to take part in the online survey and the knowledge test described above. The email explicitly stated that the survey was voluntary and anonymous. In addition, we explicitly pointed out that the potential exam questions would not be used in an official examination as part of medical school. Therefore, the students did not have to past this test. Furthermore, the students were asked not to prepare for or cheat on the test in any way, as the evaluation of the results would then lose its validity. A reminder email was sent 7-10 days after the first one.

\section{Results}

A total of up to 128 out of a possible 320 students took part in the survey (40\%). 125 participants answered all the questions and three participants answered only the knowledge questions. Since only one miss was allowed, around $70 \%$ of the participants had attended all five, about $25 \%$ four, and only $4 \%$ three seminars. 125 participants answered all the questions referring to a personal judgement of the seminar series "radiation oncology" (Fig. 1). In general, the series was well received. About $50 \%$ of the participants liked the series, with 5 points out of 6 on the Likert scale. The average was also 5.0, with only $6 \%$ awarding 3 or fewer points (standard deviation 0.9 ). The result with regard to the question that referred to the judgment on the way knowledge was provided, and the required time for it, e.g., the methodical approach, was similar (standard deviation 1.0). The response to the question about the internalization of the essential content of the seminars on a long-term basis, e.g., the effectiveness in terms of learning, however, was not quite as homogenous. Although the mean was 4.4, more than $10 \%$ of the students gave a value of 3 or less. The students' opinions on the application of alternative teaching methods or e-learning formats, in particular on the application of the flipped classroom method, differed widely. All the numbers on the scale of 1 to 5 got about the same quantity of votes. More than $40 \%$ of the students thought that they would have internalized the essential learning content better in the long term if alternative teaching methods (selfstudy or instructional videos) had been applied. The distribution of votes was more homogeneous with the question on the benefits of applying e-learning variants. Here the average was 3.4 (standard deviation 1.8).

The vast majority $(81 \%)$ of the students felt that they had internalized the essential learning content in the long term. This self-perception was contradictory to the results of the knowledge test, which were not satisfactory. In Germany, most tests of this type in the context of medical education require a minimum of $60 \%$ correct answers for the test to pass. Taking the performance of all the participants in the test into consideration, the percentage of correctly answered questions was $52 \%$ (Fig. 2). Students performed worst with regard to the two questions relating to the seminar "Informed consent discussion." Only 35 and $31 \%$, respectively, answered these questions correctly. Students performed just as poorly on the questions relating to "Target volume definition and linear accelerator." Only 51 and $20 \%$ of the answers were correct. The best overall result was achieved concerning "Radiation biology," with $66 \%$ correct answers on average. There was a great difference between these two
Fig. 2 Percentage of correctly answered questions regarding radiation oncology topics among medical students

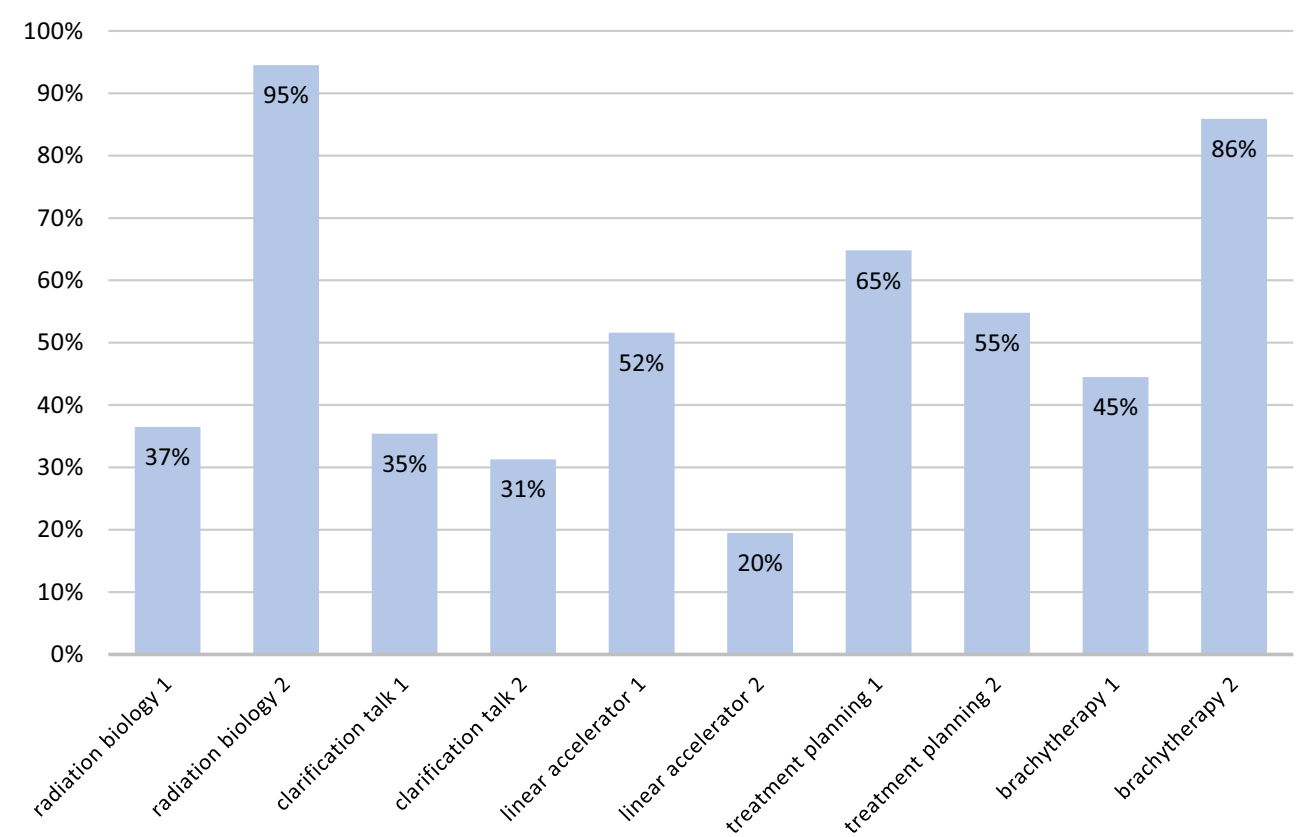


questions, with $95 \%$ correct answers to one of the questions and only $37 \%$ correct answers to the other question. The questions on "Brachytherapy" achieved an average of $65 \%$, which was almost as good as the average result for "Radiation biology." Here too, the result of one of the two questions was above average $(86 \%)$, while the other question was answered correctly by only $45 \%$ of the students. The results of the questions on "Radiation planning" (including "Radiation physics") were in the middle of the scale. The average of correct answers was $60 \%$, with the one question achieving $65 \%$ and the other question achieving $55 \%$.

\section{Discussion}

The aim of this study was to analyze the acceptance and effectiveness of traditional teaching methods in seminars concerning radiation oncology education, and to find out to what extent students might accept innovative e-learning methods. Our study showed that traditional teaching methods are largely accepted by students, but might be less effective in terms of long-term internalization. The possible use of e-learning methods is judged critically or desired in roughly equal parts among the students.

More than $96 \%$ of all participants in this sequence of seminars said they liked this sequence and the way in which knowledge was communicated. One explanation might be that students in general seem to prefer classes in smaller groups in comparison to traditional lectures [17]. The often practical relevance of the content and the interaction between teachers and students causes a more intimate character of these seminars. Although students mainly play a passive role in this format of teaching, they are taught about aspects of clinical routine work in a way that goes beyond regular lectures which are normally only PowerPoint presentations. The great diversity of ideas regarding application of e-learning methods according to the flipped classroom approach makes it difficult to implement such an approach. However, it should be taken into account that there is a possibility that some students may not have had experience with the flipped classroom teaching method and were therefore unable to adequately evaluate the potential benefits of such a format. Even if the academic pattern of types of learners according to Kolb (active vs. passive, concrete vs. abstract) cannot be empirically substantiated, and one-sided attributions do not do justice to the complex personality of the individual learner, the survey may illustrate the students' different fundamental preferences [20, 21]. About half of the students said clearly that they are basically satisfied with the current manner of learning. To them, a video as an introduction to each seminar unit would mean having to meet an additional obligation and having to spend extra time on their studies. These students obviously do not see the benefit of spending more time on the specific topic. They might also consider having a more active role in the learning process an "excessive load" of instruction. On the other hand, the other half of the students think the introduction to the current teaching session by a short video would be effective, although they are quite content with the current design of the seminars. There might be many different reasons for these two opposing opinions. For some students, the flipped classroom models might probably only get a positive rating if they had experienced this method [22]. We would suggest future analyses to elicit this issue.

In this context, the general digitalization that has conquered everyday life throughout the world might be of importance. A survey of 5000 students showed that $97 \%$ of them refer to online sources often or sometimes when studying [23]. This may lead to the conclusion that many students get convinced that this will have an additional positive effect because of the opportunity to gain a deeper understanding and remembering. However, this learning format requires more personal responsibility on the part of the students and might initially take more time [24]. Therefore it seems to be of special interest to find out to what extent the acceptance of an e-learning format might change after its introduction, and whether there might be a clear opinion in favor of or against this format. After having participated in class and not having prepared for a test, the students were able to answer only slightly more than half of all the questions on the test correctly. In the formal exam, however, more than $80 \%$ of the answers are correct on average. The students' self-perception regarding long-term internalization of the course content was much more positive and deviated strongly from their actual performance. This seems to indicate that traditional courses, especially seminars, are popular with students because of their connection to real clinical cases but do not stand for greater effectiveness with respect to long-term declarative knowledge transfer than other forms of teaching. We asked the students to answer the knowledge questions at a time when they were not yet preparing specifically for their exams. We asked them urgently not to specifically study for this test. The current education system means that students mainly start learning just shortly before the exam, and forget the main contents quickly afterwards ("bulimic learning") [25]. A timespan of 1 to 7 weeks with all five seminar units seemed appropriate to us to ensure that on the one hand, the testing of the long-term memory relating to the reproduction of knowledge took place, and on the other hand, the time gap to the seminars was not too long. The results, however, reveal the importance of an additional individual repetition of the content learned in the seminar [26, 27]. Repetition could take little time if the major information given in class was introduced by a teaching video before the respective seminar, though. Thus, the additional time originally anticipated for 
conveying class contents and deepening knowledge would be put into perspective, since clearly less time for processing the information given and preparing for the exam would probably be needed.

The implementation of e-learning methods, especially of instructional videos in the run-up to an in-depth seminar is complex, particularly in a cross-sectional subject such as radiation oncology. Radiation oncology combines very abstract theoretical aspects (radiation physics, radiation biology) with practically oriented clinical aspects such as explanatory conversation with the patient, patient treatment, and technical applications such as planning CT creation and target volume definition on multimodal imaging. Due to this complexity, the different aspects can be taught as a whole via e-learning, because theoretical and practical aspects can be combined in a short time. This means, however, that the learning objectives have to be reduced to essential aspects. A short learning video of about $10 \mathrm{~min}$, for example, may serve this purpose, as the structuring of the video can be optimized and the content can be selected and fully covered in advance. After the video has been produced, knowledge can be transferred outside of class without being dependent on experts or being bound to a location (e.g., in the event of illness or equipment failure), and can be accessed indefinitely and deepened at an individual pace. In this way, education can assure quality in general by utilizing instructional videos [28]. In addition, a well-made educational video should offer the opportunity to put it to use repeatedly as a self-contained unit and to understand its content without requiring much previous knowledge. Furthermore, the use of instructional videos, especially in radiation oncology, has many positive side effects. For example, brachytherapy sources may be filmed once from different perspectives in an adequate way and at high resolution, and then be presented and explained with an explanatory audio track. As a result, a presentation in class is not needed anymore, which is to be welcomed because of protection against radiation. Important aspects become redundant since they are prepared individually, and are repeated or applied in class. Repeating important aspects is substantial for a positive long-term memory performance $[26,27,29]$. Studies have also shown that active use of acquired knowledge by means of managing a specific task, for example independent conduct of an oncological informed consent discussion, is of higher value than absorbing information in a rather passive way by listening to or watching information given [27, 30-33]. Therefore, the gained time by individual preparation should be used to offer students adequate practical training, or any other way of active participation. In addition, if theoretical knowledge is connected to practical exercises, e.g., target volume definition on axial CT slices, the integration of different objectives of learning, e.g., explain target volume, recognize CT anatomy, will be reached more easily. This offers the opportunity to understand the content more deeply and remember it on a longterm basis [34]. The evidence for the effectiveness of active, cooperative, and problem-based learning is given [35]. Besides this, the chance for students to work in small groups on specific tasks leads to an increased team spirit and thus improves the students' communication skills [34-36]. In class, the teacher adopts the position of the expert who answers any remaining questions arising from the instructional videos and may work as a moderator by asking specific questions, providing tasks, and giving supplementary information. Overall, according to several studies, flipped classroom improves student learning in terms of internalizing deep understanding of complex contents [32].

However, e-learning or flipped classroom needs a lot of preparation time and reveals its weaknesses as soon as students come to class without being sufficiently prepared [4, 24]. For these students it will be difficult to actively participate in the discussion [37] and therefore to learn effectively.

At the Technical University of Munich, we are gaining first experience in applying modern e-learning methods in the fields of radiation oncology. On the basis of the quality criteria mentioned above, we produced educational videos of 8-10 min for each seminar. Experts in the field of medical education and so-called eScouts (medical students who are trained to assist and advice teachers with the implementation of e-learning formats) assisted us. The new teaching format was supposed to be launched and tested in the summer term of 2020. Unfortunately, we will have to postpone comparison of performance with students of later terms because of the decision not to have face-to-face teaching during this period due to the SARS-CoV-2 pandemic. We were lucky to have the production of the videos completed before this decision was made, because we were therefore able to use them as teaching material in this presence-free summer term due to the COVID-19 crises. What a wonderful, though unintentional, additional argument in favor of establishing well thought out e-learning formats.

\section{Limitations}

The significance of the test results is limited, because due to the technical implementation of the test, we could not perform a basic quantitative analysis of the examination [38]. The analysis of item difficulty and discrimination is missing. Hence, the reliability and significance of the examination could not be determined. However, the quality criteria applied to our questions matched those of high-quality multiple-choice questions. The questions were created by the same experienced questioners as the regular examinations during the medical curriculum, and could be answered regularly with the content of the handouts for each seminar. Furthermore, it is difficult to assess the acceptance of the 
students regarding the implementation of e-learning content (question 7), because it is unclear to what extent the students could imagine such a format. Both aspects can best be substantiated by a direct comparison after establishing the new e-learning format, which will take place after the next semesters with mandatory attendance of the students.

\section{Conclusion}

Traditional seminars enjoy a high level of acceptance among students. Effectiveness with regard to the internalization of content taught, however, should be increased. After all, the future seems to lie in the integration of e-learning in the form of educational videos and practical seminars, because there are many advantages associated with this way of learning.

Author Contribution All co-authors contributed to the design of the study. HD designed and coordinated the study, created the survey and test questions, organized and carried out student teaching, evaluated the results, and wrote the manuscript. SC and DB made substantial contributions to conception and design of the study, organized student teaching, and interpreted data. MW and PB provided the theoretical background knowledge regarding the teaching sciences in the field of medical studies and contributed to conception and design of the study, interpreted data, and revised the manuscript. SR, KM, and IK carried out the technical implementation of the survey and the test, performed the evaluations of the student survey, created figures, and were in contact with the students. All co-authors read and revised the manuscript. The final version of the manuscript was approved by all co-authors.

Funding Open Access funding enabled and organized by Projekt DEAL.

Conflict of interest H. Dapper, M. Wijnen-Meijer, S. Rathfelder, K. Mosene, I. von Kirchbauer, D. Bernhardt, P.O. Berberat, and S.E. Combs declare that they have no competing interests.

Open Access This article is licensed under a Creative Commons Attribution 4.0 International License, which permits use, sharing, adaptation, distribution and reproduction in any medium or format, as long as you give appropriate credit to the original author(s) and the source, provide a link to the Creative Commons licence, and indicate if changes were made. The images or other third party material in this article are included in the article's Creative Commons licence, unless indicated otherwise in a credit line to the material. If material is not included in the article's Creative Commons licence and your intended use is not permitted by statutory regulation or exceeds the permitted use, you will need to obtain permission directly from the copyright holder. To view a copy of this licence, visit http://creativecommons.org/licenses/by/4. $0 /$.

\section{References}

1. Oertel M, Linde P, Mäurer M et al (2020) Quality of teaching radiation oncology in Germany-where do we stand? : Results from a 2019 survey performed by the working group "young DEGRO" of the German Society of Radiation Oncology. Strahlenther Onkol 196(8):699-704
2. Tagesspiegel (ed) (2020) Medizinstudium: Pauken macht den Arzt - Wissen. https://www.tagesspiegel.de/wissen/medizinstudiumpauken-macht-den-arzt/1642764.html. Accessed 13 May 2020

3. Nikendei C, Weyrich P, Jünger J et al (2009) Medical education in Germany. Med Teach 31(7):591-600. https://doi.org/10.1080/ 01421590902833010

4. Williams DE (2016) The Future of Medical Education: Flipping the Classroom and Education Technology. Ochsner J 16(1):14-15

5. Bi M, Zhao Z, Yang J et al (2019) Comparison of case-based learning and traditional method in teaching postgraduate students of medical oncology. Med Teach 41(10):1124-1128. https://doi.org/ 10.1080/0142159X.2019.1617414

6. Pershing S, Fuchs VR (2013) Restructuring medical education to meet current and future health care needs. Acad Med 88(12):1798-1801. https://doi.org/10.1097/ACM.00000000000000 20

7. Wynter L, Burgess A, Kalman E et al (2019) Medical students: what educational resources are they using? BMC Med Educ 19(1):36. https://doi.org/10.1186/s12909-019-1462-9

8. Gehlen-Baum V, Weinberger A (2012) Notebook or Facebook? How students actually use mobile devices in large lectures. In: Hutchison D, Kanade T, Kittler J et al (eds) 21 century learning for 21 century skills 7th European Conference on Technology Enhanced Learning, EC-TEL 2012, Saarbrücken, 18-21.09. Springer, Berlin, pp 103-112 (Proceedings)

9. Williams DE (2016) The future of medical education: flipping the classroom and education technology. Ochsner J 16(1):14-15

10. Moffett J (2015) Twelve tips for "flipping" the classroom. Med Teach 37(4):331-336. https://doi.org/10.3109/0142159X.2014. 943710

11. Prober CG, Khan S (2013) Medical education reimagined: a call to action. Acad Med 88(10):1407-1410. https://doi.org/10.1097/ ACM.0b013e3182a368bd

12. Srinivasan DK (2020) Medical students' perceptions and an anatomy teacher's personal experience using an e-learning platform for tutorials during the Covid-19 crisis. Anat Sci Educ. https://doi. org/10.1002/ase. 1970

13. Iyer P, Aziz K, Ojcius DM (2020) Impact of COVID-19 on dental education in the United States. J Dent Educ. https://doi.org/10. $1002 /$ jdd. 12163

14. Wannenmacher M, Wenz F, Debus J (eds) (2013) Strahlentherapie, 2nd edn. Springer-Medizin, Berlin (Mit 298 Tabellen)

15. Duma M-N (2020) Die Herzmortalität nach Strahlentherapie, Chemotherapie und endokriner Therapie des Mammakarzinoms (Cardiac mortality after radiotherapy, chemotherapy and endocrine therapy for breast cancer). Strahlenther Onkol. https://doi.org/10. 1007/s00066-020-01649-1

16. Oertel M, Schmitz M, Becker JC et al (2019) Erfolgreiche Integration der Radioonkologie in die präklinische medizinische Ausbildung : Erfahrungen mit einem interdisziplinären Lehrprojekt (Successful integration of radiation oncology in preclinical medical education : Experiences with an interdisciplinary training project). Strahlenther Onkol 195(12):1104-1109. https://doi.org/10.1007/ s00066-019-01492-z

17. Costa ML, van Rensburg L, Rushton N (2007) Does teaching style matter? A randomised trial of group discussion versus lectures in orthopaedic undergraduate teaching. Med Educ 41(2):214-217. https://doi.org/10.1111/j.1365-2929.2006.02677.x

18. Electric Paper Evaluationssysteme (2020) Umfrage Software und Prüfungsplattform. https://www.evasys.de/startseite.html. Accessed 13 May 2020

19. Walsh K (2005) Advice on writing multiple choice questions (MCQs). BMJ 330(7483):s25.2-s27. https://doi.org/10.1136/bmj. 330.7483.s25-a 
20. Widulle W (2009) Handlungsorientiert Lernen im Studium. Arbeitsbuch für soziale und pädagogische Berufe, 1st edn. VS, Wiesbaden

21. Kolb DA (1984) Experimental learning. Experience as the source of learning and development vol 1. Prentice-Hall, Englewood Cliffs, London

22. Lee YH, Kim K-J (2018) Enhancement of student perceptions of learner-centeredness and community of inquiry in flipped classrooms. BMC Med Educ 18(1):242. https://doi.org/10.1186/s12909018-1347-3

23. (2018) Studie: Diese Lernmittel nutzen Studis am liebsten. https:// www.unicum.de/de/aktuelles/news/studie-diese-lernmittel-nutzenstudis-am-liebsten. Accessed 15 May 2020

24. Müller C, Füngerlings S, Tolks D et al (2018) Teaching load-a barrier to digitalisation in higher education? A position paper on the framework surrounding higher education medical teaching in the digital age using Bavaria, Germany as an example. GMS J Med Educ 35(3):Doc34. https://doi.org/10.3205/zma001180

25. Precht RD (2020) Wir brauchen eine Bildungsrevolution! https:// www.cicero.de/kultur/wir-brauchen-eine-bildungsrevolution/ 51963. Accessed 11 June 2020

26. Friedlander MJ, Andrews L, Armstrong EG et al (2011) What can medical education learn from the neurobiology of learning? Acad Med 86(4):415-420. https://doi.org/10.1097/ACM. 0b013e31820dc197

27. Mann KV (2002) Thinking about learning: implications for principle-based professional education. J Contin Educ Health Prof 22(2):69-76. https://doi.org/10.1002/chp.1340220202

28. Dombrowski T, Wrobel C, Dazert S et al (2018) Flipped classroom frameworks improve efficacy in undergraduate practical courses - a quasi-randomized pilot study in otorhinolaryngology. BMC Med Educ 18(1):294. https://doi.org/10.1186/s12909-0181398-5

29. Versteeg M, Hendriks RA, Thomas A et al (2020) Conceptualising spaced learning in health professions education: a scoping review. Med Educ 54(3):205-216. https://doi.org/10.1111/medu.14025
30. Zottmann JM, Dieckmann P, Taraszow T et al (2018) Just watching is not enough: fostering simulation-based learning with collaboration scripts. GMS J Med Educ 35(3):Doc35. https://doi.org/10. 3205/zma001181

31. Taylor DCM, Hamdy H (2013) Adult learning theories: implications for learning and teaching in medical education: AMEE Guide No. 83. Med Teach 35(11):e1561-72. https://doi.org/10. 3109/0142159X.2013.828153

32. Hew KF, Lo CK (2018) Flipped classroom improves student learning in health professions education: a meta-analysis. BMC Med Educ 18(1):38. https://doi.org/10.1186/s12909-018-1144-z

33. Bouwmeester RAM, de Kleijn RAM, van den Berg IET et al (2019) Flipping the medical classroom: effect on workload, interactivity, motivation and retention of knowledge. Comput Educ 139(1):118-128

34. Dennick R (2012) Twelve tips for incorporating educational theory into teaching practices. Med Teach 34(8):618-624. https://doi.org/ 10.3109/0142159X.2012.668244

35. Prince M (2004) Does active learning work? A review of the research. J Eng Educ 93(3):223-231. https://doi.org/10.1002/j.21689830.2004.tb00809.x

36. Cantillon P, Wood DF, Yardley S (2017) ABC of learning and teaching in medicine, 3rd edn. ABC series. Wiley, Hoboken

37. Drummer J Einfluss verschiedener Typen online basierter Lernplattformen auf die Kompetenz - und Leistungsentwicklung von Schülern. Technische Universität Dresden. https://nbn-resolving. org/urn:nbn:de:bsz:14-ds-1232884068861-14322

38. Moeltner A, Schellberg D, Juenger J (2006) Grundlegende quantitative Analysen medizinischer Prüfungen [Basic quantitative analyses of medical examinations]. GMS Z Med Ausbild 23(3). https:// nbn-resolving.org/urn:nbn:de:bsz:14-ds-1232884068861-14322 